\title{
Damage Assessment of Bitumen Refineries Using Simapro (LCA) Inventory Data
} Saeed Morsali*

Faculty of Applied Sciences, Department of Environmental Science, Gazi University, Ankara, Turkey

\begin{abstract}
Oil refineries are complex facilities. Several processes, such as distillation, vacuum distillation, or steam reforming are required to produce a large variety of oil products such as gasoline, light fuel oil or bitumen. The environmental impacts of oil refineries are assessed using the technique of life cycle assessment (LCA). In this paper, only the material production phase of the bitumen life cycle is considered. To improve the quality of the LCA, a regionalized life cycle inventory $(\mathrm{LCl})$ database for the Oil refineries and commercial $\mathrm{LCl}$ databases are used to validate and model unit processes with LCA software.
\end{abstract}

Keywords: Bitumen refinery; LCA: Life Cycle Assessment; Damage assessment of bitumen; Simapro

\section{Introduction}

The importance of quantifying the impact of products and services on the environment is growing due to the recent changes in patterns of climate, living and ecosystem quality. Consumers and governments are increasingly demanding information about the sustainability of products and interest in comparing potential solutions based upon scientific data is necessary in order to do this.

Petroleum refining is a unique and critical link in the petroleum supply chain, from the wellhead to the pump. The other links add value to petroleum mainly by moving and storing it (e.g., lifting crude oil to the surface; moving crude oil from oil fields to storage facilities and then to refineries; moving refined products from refinery to terminals and end-use locations, etc.). Refining adds value by converting crude oil (which in itself has little end-use value) into a range of refined products, including transportation fuels. The primary economic objective in refining is to maximize the value added in converting crude oil into finished products. Petroleum refineries are large, capital-intensive manufacturing facilities with extremely complex processing schemes. They convert crude oils and other input streams into dozens of refined (co-products) including:

a. Liquefied petroleum gases (LPG).

b. Gasoline.

c. Jet fuel.

d. Kerosene (for lighting and heating).

e. Diesel fuel.

f. Petrochemical feedstocks.

g. Lubricating oils and waxes.

h. Home heating oil.

i. Fuel oil (for power generation, marine fuel, industrial and district heating).

j. Asphalt (for paving and roofing uses).

Of these, the transportation fuels have the highest value; fuel oils and asphalt the lowest value. Many refined products, such as gasoline, are produced in multiple grades, to meet different specifications and standards (e.g., octane levels, sulfur content). More than 660 refineries, in 116 countries, are currently in operation, producing more than 85 million barrels of refined products per day (1:2011:2). Each refinery has a unique physical configuration, as well as unique operating characteristics and economics. A refinery's configuration and performance characteristics are determined primarily by the refinery's location, vintage, availability of funds for capital investment, available crude oils, product demand (from local and/or export markets), product quality requirements, environmental regulations and standards, and market specifications and requirements for refined products.

In published studies about petroleum industry life cycle assessments the most focused subjects are energy consumption and some emissions such as $\mathrm{CO}_{2}, \mathrm{CO}, \mathrm{SO}_{2}$, SO. In this study the analysis lead to product specific allocation factors for energy, airborne and waterborne pollutants. Furthermore working material consumption, additive requirements, production waste, and infrastructure are included [1-3].

\section{Typical refineries}

Petroleum refining first began in earnest as a value-added process in 1856 near the site where the Killing Holm/Humber refinery sits today. Today's refineries are decidedly more sophisticated than in 1856 and rely on a fixed configuration that produces fixed output depending on the quality of the crude inputs and the capacity of the refinery. There are several processes involved in processing crude inputs to make them useable and marketable fuel outputs. The main refining processes can be described in terms of the order in which they occur. The most common form of petroleum refining is known as fractional or atmospheric distillation, which involves pumping the crude petroleum into the bottom of a heated column and then separating the fuels via different temperature levels (Energy Institute). All fuels go through the initial distillation process to separate from crude oil on the way to further processing. The residue of the distillation column, much heavier than crude oil is then sent to a second distillation unit while the other fuel products are sent to other processes. The lightest

"Corresponding author: Saeed Morsali, Faculty of Applied Sciences, Department of Environmental Science, Gazi University, Ankara, Turkey, Tel: +90312 2126840; E-mail: morsali.saeed@gmail.com

Received November 29, 2016; Accepted January 30, 2017; Published February 05, 2017

Citation: Morsali S (2017) Damage Assessment of Bitumen Refineries Using Simapro (LCA) Inventory Data. J Pet Environ Biotechnol 7: 317. doi: 10.4172/2157 7463.1000317

Copyright: (c) 2017 Morsali S. This is an open-access article distributed under the terms of the Creative Commons Attribution License, which permits unrestricted use, distribution, and reproduction in any medium, provided the original author and source are credited. 


\section{Global Bitumen use (million metric tonnes per year)}

\section{Bitumen Applications}

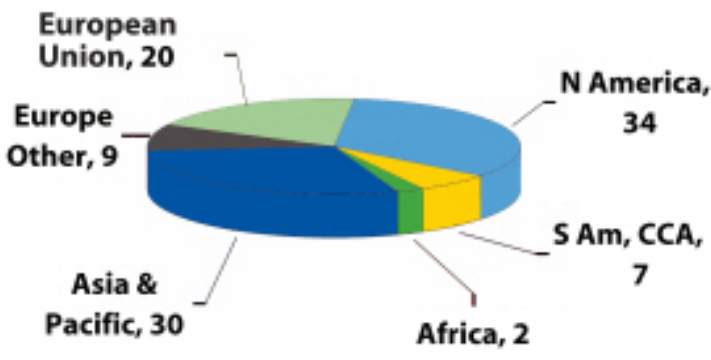

Total: 102 MT per Year

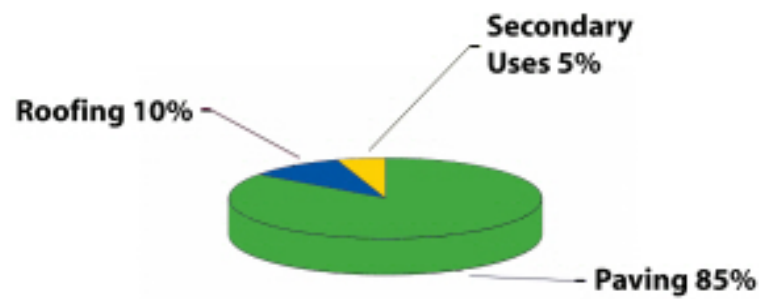

Figure 1: Global bitumen use and application areas.

products, liquefied petroleum gases, mostly butane, propane and naphtha require little to no further processing in order to be sold to market. However, other products require more processing in order to become marketable. The main fuel products can be classified in the same way as the distillation column for simplicity's sake. The lighter products within the column rise while the heavier products sink [48]. The additional processing that occurs can be summarized by fuel type and carbon structure. Liquid petroleum gases (LPG) are most commonly in the form of naphtha, butane and propane. LPGs typically require little to no further processing except for sulfur removal. Sulfur removal (desulfurization) is also entirely dependent on the source of the crude and how much sulfur it contains. Petrol is generally removed from the distillation unit and cleaned in what is called a unifiner. A unifiner removes sulfur and nitrogen compounds in the fuel and creates hydrogen sulfide and ammonia as wastes. Then the molecular structure is modified to increase the octane levels of the fuel so that it is suitable for combustion in motor vehicles and other petrol burning engines. Sulfur is a by-product of this process and is recycled in other processes or sent to waste processing. Petrol can also be separated from the heavy distillate residues through a process called catalytic cracking. Generally the more complex plants have catalytic crackers and are capable of refining heavier fuels. Catalytic cracking is an additional process and while adding value, also adds cost and emissions. The last step in petrol processing is fuel blending as required by national fuel specifications guided by the European Fuel Quality Directive. Jet fuel and kerosene are generally grouped together because they have a similar carbon structure. They emerge from the distillation process requiring desulfurization. This is done through what is known as a merox unit, which washes the fuel with sodium hydroxide (caustic washing) and other additives which also help to reduce the impurities in the fuel. Diesel and gas oil are used for combustion engines and heating purposes mostly. They require post-distillation processing in a unit known as a hydrotreater. The hydrotreater removes sulphur and other impurities using hydrogen recycled from other processes as a catalyst. The diesel and gas oil is typically ready for market after this process. Fuel oils are generally used for heating and ship transport. These fuels require additional distillation through a process known as vacuum distillation. Vacuum distillation is a similar process to the primary distillation process except that the pressure within the distillation column is greatly reduced so that additional lighter fuels can be separated and captured for further processing. The lighter fuels that come out of the vacuum distillation unit are sent to a catalytic cracking unit and separated by fuel type to go through the remaining refining processes. Finally, Bitumen is obtained by vacuum distillation or vacuum flashing of atmospheric residue from the vacuum distillation column. This is "straight run bitumen". This process is called bitumen production by straight run vacuum distillation [9-12].

An alternative method of bitumen production is by precipitation from residual fractions by propane or butane-solvent deasphalting. The bitumen thus obtained has properties which derive from the type of crude oil processed and from the mode of operation in the vacuum unit or in the solvent deasphalting unit. The grade of the bitumen depends on the amount of volatile material that remains in the product: the smaller the amount of volatiles, the harder the residual bitumen.

It is estimated that the current world use of bitumen is approximately 102 million tons per year. The primary use of bitumen is for paving and roofing applications; $85 \%$ of all the bitumen is used as the binder in various kind of asphalt pavements: Pavements for roads, airports, parking lots, etc.

About $10 \%$ of the bitumen is used for roofing. The rest of the bitumen, approximately $5 \%$ of the total, is used for variety of purposes, each very small in volume. This sector is referred to as "secondary uses" (2: 2011:2),

This figure shows estimated yearly bitumen production worldwide by different area, it also represents bitumen applications by sector (Figure 1).

\section{Inventory Analysis}

In this study database for emission factors for the Swiss and for the average Western European refinery are used. Airborne emissions comprise $\mathrm{CO}, \mathrm{CO}_{2}, \mathrm{SO}_{2}, \mathrm{NO}_{\mathrm{x}}$, particulate matter, hydrocarbons (specified), acids and heavy metals (specified). Waterborne pollutants comprise hydrocarbons (specified), and inorganic substances (sulfates, phosphates and nitrate). Different production waste and their further treatment are distinguished. The environmental impacts modeled include energy consumption and greenhouse gas (GHG) emissions from oil refineries.

\section{System boundaries}

The model describes the production of oil products for energetic and partly non energetic uses and the production of thermal energy and electricity in Switzerland and Western Europe. The inventory tables for oil products include oil field exploration, crude oil production, long 


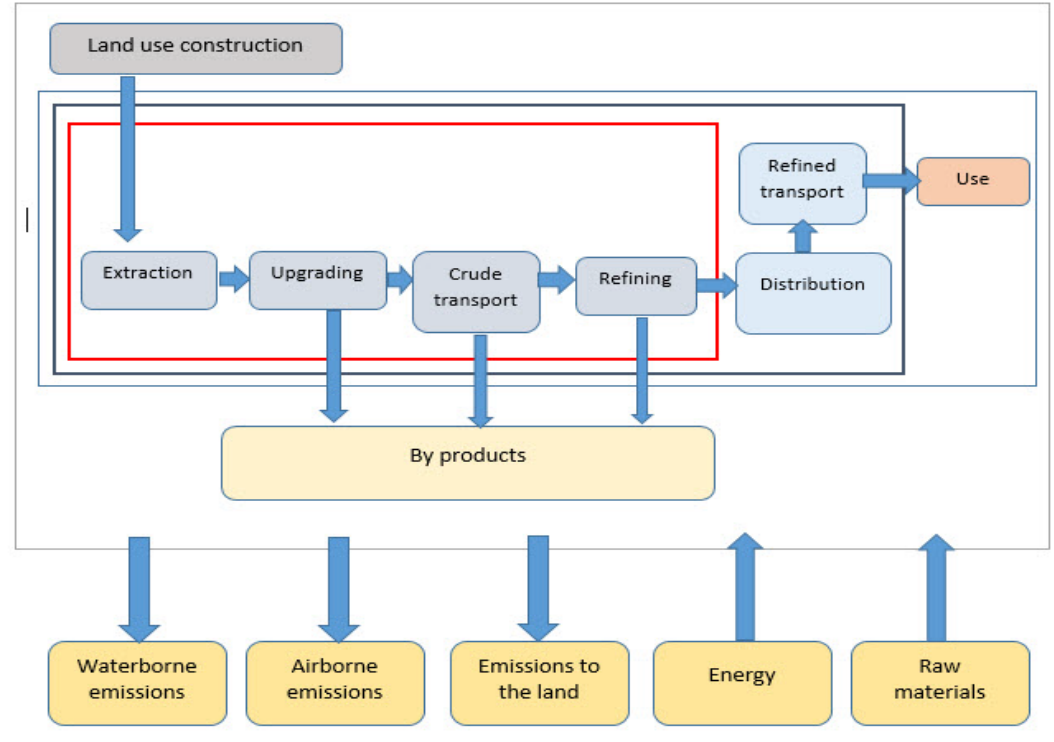

Figure 2: System boundary for bitumen production.

distance transportation, oil refining, regional distribution and the use of oil products in domestic and industrial boilers, in power plants and in spark ignition engines (of trucks, personal cars, excavator, locomotives and ships).

For all these steps air and waterborne pollutants as well as energy and working material requirements, production waste, and the production of the equipment are considered $[13,14]$.

This study covers the bitumen production chain, starting from raw material extraction and ending with a bitumen product ready for delivery to a customer. The process is divided into four stages: crude oil extraction, transport, production and storage. A schematic description of the system boundary is given in Figure 2 .

\section{Inventory data}

Inventory data for this study is taken from commercial Simapro 7.1 program database and the oil fuel chain in particular is divided into the following process steps:

Oil field exploration: Include emissions caused by drilling activities, barite and bentonite consumption and the emissions of oily drilling fluids into the sea (emission data for North Sea exploration is used).

Crude oil production: The variation in drilling efforts and energy consumption per barrel oil extracted between different regions is modeled.

Long distance transportation: Distance is used according to the specific supply situation of Switzerland and Western Europe.

Oil refining: Regional distribution: Regional distribution includes storage in large stock and the supply to the costumer. The requirements and emissions during the regional distribution are considered. The infrastructure and the energy consumption for the movement of goods, production waste and hydrocarbon emissions are included.

Fuel oil boilers: Three different sizes of boilers are considered, namely $10 \mathrm{KW}, 100 \mathrm{KW}$ and $1 \mathrm{MW}$ and also manufacturing of boilers including tank room and chimney is considered.

\section{Impacts assessment of bitumen refineries}

For this paper the used method is ECO INDICATOR 99 which has three main impact categories; human health, ecosystem quality and resources. Simapro uses Pt unit to show these impacts. The Pt unit used in eco indicator method defined as a dimensionless value. The value of $1 \mathrm{Pt}$ means one thousandth of the yearly environmental load of one average European inhabitant. The environmental impact scores of life cycle assessments are often presented in units that are difficult to grasp, such as $\mathrm{kg} \mathrm{CO}_{2}$ equivalents or CTUh. One way to make interpreting such scores easier is to normalize them: dividing your scores by a reference situation's scores. This reference situation could be one person's - Average Joe's - share of all emission and resource use in the world during one year. Normalization converts complicated units into fractions of Joe's scores per impact category (3: 2000: 9) (Figure 3 and Graph 1) [14]. The scores for climate change, human toxicity, and many other impact categories are all compared to the annual impact Average Joe has, and expressed in fractions. For 1 ton bitumen production the following values are analyzed.

Resources: Mankind will always extract the best resources first, leaving the lower quality resources for future extraction. The damage of resources will be experienced by future generations, as they will have to use more effort to extract remaining resources. This extra effort is expressed as "surplus energy".

As the Table 1 shows the highest impact accrues in resources category and the Figure 4 represents a tree analysis for resource category, a tree analysis shows all processes which cause any impact on resources as well as their share in whole resource depletion process. Figure 4 also shows the priority of the process.

Under this category Eco-Indicator 99 considers two main impacts, namely fossils fuels and minerals:

Minerals: Surplus energy per kg mineral or ore, as a result of decreasing ore grades.

Fossil fuels: Surplus energy per extracted MJ, $\mathrm{kg}$ or $\mathrm{m}^{3}$ fossil fuel, as a result of lower quality resources. 
Citation: Morsali S (2017) Damage Assessment of Bitumen Refineries Using Simapro (LCA) Inventory Data. J Pet Environ Biotechnol 7: 317. doi: 10.4172/2157-7463.1000317

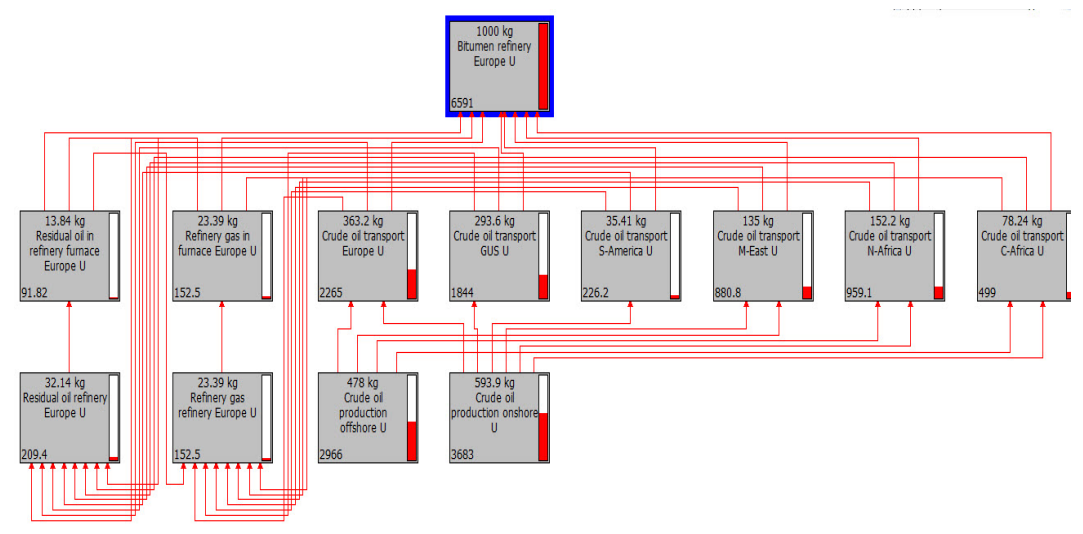

Figure 3: Damage assessment's Tree analyses for resource category.

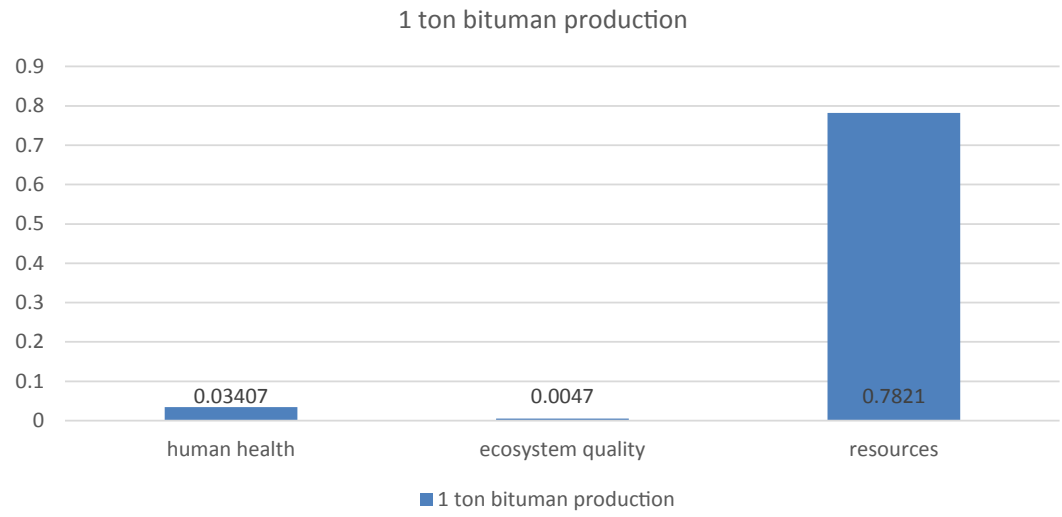

Graph 1: Normalization of 1 ton bitumen production.

\begin{tabular}{|c|c|c|c|c|c|}
\hline No & Substance & Compartment & Sub-Compartment & Unit & Bitumen refinery Europ \\
\hline & Total of all compartments & & & MJ surplus & 6591 \\
\hline 1 & Oil, crude, $42.6 \mathrm{MJ}$ per kg, in ground & Raw & in ground & MJ surplus & 6572 \\
\hline 2 & Gas, natural, $35 \mathrm{MJ}$ per $\mathrm{m} 3$, in ground & Raw & in ground & MJ surplus & 12.84 \\
\hline 3 & Coal, $18 \mathrm{MJ}$ per kg, in ground & Raw & in ground & MJ surplus & 2.889 \\
\hline 4 & Tin, in ground & Raw & in ground & MJ surplus & 1.127 \\
\hline 5 & Gas, mine, off-gas, process, coal miningil<g & Raw & in ground & MJ surplus & 0.8796 \\
\hline 6 & Copper, in ground & Raw & in ground & MJ surplus & 0.7595 \\
\hline 7 & Iron, in ground & Raw & in ground & MJ surplus & 0.2661 \\
\hline 8 & Nickel, in ground & Raw & in ground & MJ surplus & 0.07882 \\
\hline 9 & Bauxite, in ground & Raw & in ground & MJ surplus & 0.02575 \\
\hline 10 & Lead, in ground & Raw & in ground & MJ surplus & 0.02292 \\
\hline 11 & Chromium, in ground & Raw & in ground & MJ surplus & 0.004774 \\
\hline
\end{tabular}

Table 1: Damage assessment of Substances which are effect on resources.

Table 1 shows substances which effect on resource during bitumen production, the unit used for this table is $\mathrm{MJ}$ surplus which explained earlier. Also Table 1 shows the nature of these substances in case of how they released in environment and where they release like ground or as gases in the air.

Human health: Damage to human health, expressed as the number of year life lost and the number of years lived disabled. These are combined as Disability Adjusted Life Years (DALYs), an index that is also used by the World Bank and the WHO (4: 2016: 53). This category includes; climate change, ozone layer depletion, carcinogenic effects, respiratory effects and ionising radiation.
The Figure 4 is a tree analysis for human health category; all processes which have any effect on human health are shown as a tree with their impact share and their relevance which each other. The unit used for Figure 4 is DALY unit.

Human health category includes six subcategories which shown in the Tables 2 and 3; Carcinogenic affects due to emissions of carcinogenic substances to air, water and soil, Respiratory organics effects resulting from summer smog, due to emissions of organic substances to air, causing respiratory effects. Respiratory inorganics effects resulting from winter smog caused by emissions of dust, sulphur and nitrogen oxides to air. Climate change Damage, resulting from an increase of diseases and death caused by climate change. Radiation Damage, 
Citation: Morsali S (2017) Damage Assessment of Bitumen Refineries Using Simapro (LCA) Inventory Data. J Pet Environ Biotechnol 7: 317. doi: 10.4172/2157-7463.1000317

Page 5 of 6

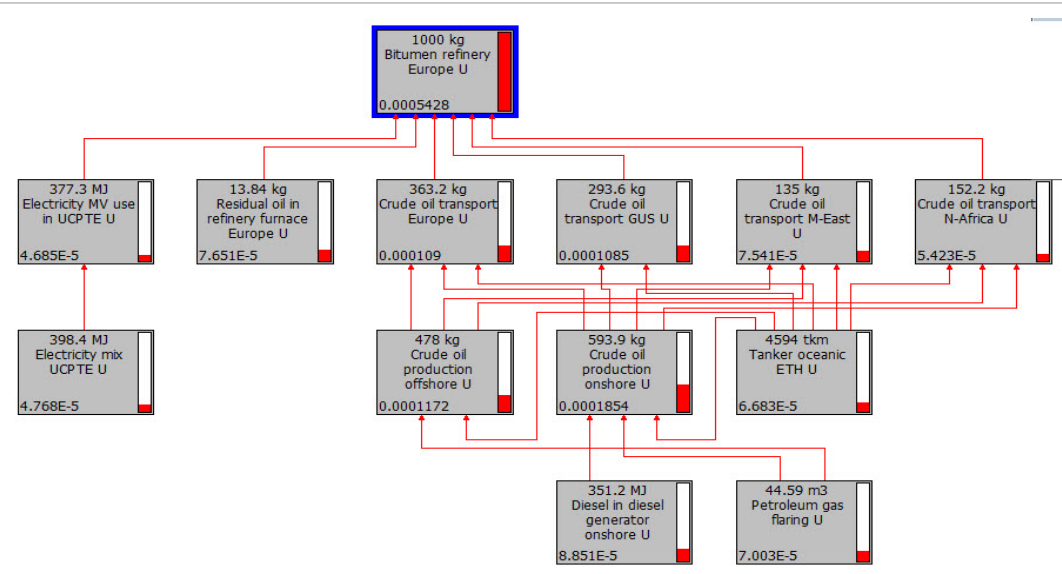

Figure 4: Damage assessment's Tree analyses for human health.

\begin{tabular}{|c|c|c|c|c|}
\hline No & Substance & Compartment & Unit & Bitumen refinery Europ \\
\hline 1 & Nitrogen oxides & Air & DALY & 0.0001783 \\
\hline 2 & Sulfur oxides & Air & DALY & 0.0001415 \\
\hline 3 & Carbon dioxide & Air & DALY & 0.00009124 \\
\hline 4 & Particulates, $<10$ um (stationary) & Air & DALY & 0.00006937 \\
\hline 5 & Methane & Air & DALY & 0.00001894 \\
\hline 6 & NMVOC, non-methane volatile organic compounds, unspecified origin & Air & DALY & 0.00001028 \\
\hline 7 & Particulates, < 10 um (mobile) & Air & DALY & 0.000007473 \\
\hline 8 & Arsenic, ion & Water & DALY & 0.00000714 \\
\hline 9 & Cadmium & Air & DALY & 0.000005344 \\
\hline 10 & Cadmium, ion & Water & DALY & 0.000004691 \\
\hline 11 & Methane, bromotrifluoro-, Halon 1301 & Air & DALY & 0.000002287 \\
\hline 12 & PAH, polycyclic aromatic hydrocarbons & Water & DALY & 0.000001817 \\
\hline 13 & Radon-222 & Air & DALY & 0.000001528 \\
\hline 14 & Dinitrogen monoxide & Air & DALY & 7.796E-07 \\
\hline 15 & Arsenic & Air & DALY & $6.176 \mathrm{E}-07$ \\
\hline 16 & Arsenic & Soil & DALY & 3.253E-07 \\
\hline 17 & Carbon monoxide & Air & DALY & 2.046E-07 \\
\hline 18 & Carbon-14 & Air & DALY & $1.522 \mathrm{E}-07$ \\
\hline 19 & Butane & Air & DALY & $1.129 \mathrm{E}-07$ \\
\hline 20 & Cesium-137 & Water & DALY & $9.505 E-08$ \\
\hline 21 & Pentane & Air & DALY & 8.727E-08 \\
\hline 22 & Propane & Air & DALY & $8.152 E-08$ \\
\hline 23 & Nickel & Air & DALY & 4.684E-08 \\
\hline 24 & Hexane & Air & DALY & 4.137E-08 \\
\hline 25 & Ethane, 1,2-dichloro-1, 1,2,2-tetrafluoro-, CFC-114 & Air & DALY & 3.011E-08 \\
\hline 26 & Benzene & Water & DALY & $2.881 \mathrm{E}-08$ \\
\hline 27 & Benzene & Air & DALY & 2.47E-08 \\
\hline 28 & Heptane & Air & DALY & 2.144E-08 \\
\hline 29 & Ammonia & Air & DALY & 2.057E-08 \\
\hline 30 & Xylene & Air & DALY & $1.785 \mathrm{E}-08$ \\
\hline 31 & Radon-222 & Air & DALY & 1.679E-08 \\
\hline 32 & Toluene & Air & DALY & $1.624 \mathrm{E}-08$ \\
\hline 33 & Hydrocarbons, aliphatic, alkanes, unspecified & Air & DALY & $1.588 \mathrm{E}-08$ \\
\hline 34 & Cobalt-60 & Water & DALY & 1.156E-08 \\
\hline 35 & Ethene & Air & DALY & $1.078 \mathrm{E}-08$ \\
\hline 36 & Propene & Air & DALY & $9.234 \mathrm{E}-09$ \\
\hline 37 & Cesium-134 & Water & DALY & 8.503E-09 \\
\hline
\end{tabular}

Table 2: Damage assessment of 1 ton bitumen production on human health

\begin{tabular}{|c|c|c|c|c|}
\hline S. No. & Substance & Compartment & Unit & Bitumen refinery Europe \\
\hline 1 & Nitrogen oxides & Air & PDF'm2yr \\
\hline 2 & Nickel & Air & PDF'm2yr & 7.49 \\
\hline
\end{tabular}


Citation: Morsali S (2017) Damage Assessment of Bitumen Refineries Using Simapro (LCA) Inventory Data. J Pet Environ Biotechnol 7: 317. doi: 10.4172/2157-7463.1000317

Page 6 of 6

\begin{tabular}{|c|c|c|c|c|}
\hline 3 & Land use $11-111$ & Raw & PDF'm2yr & 2.736 \\
\hline 4 & Sulfur oxides & Air & PDF'm2yr & 2.698 \\
\hline 5 & Land use I I-IV & Raw & PDF'm2yr & 1.611 \\
\hline 6 & Land use 111-IV & Raw & PDF'm2yr & 1.297 \\
\hline 7 & Zinc & Air & PDF'm2yr & 0.789 \\
\hline 8 & Cadmium & Air & PDF'm2yr & 0.382 \\
\hline 9 & Lead & Air & PDF'm2yr & 0.3082 \\
\hline 10 & Chromium & Air & PDF'm2yr & 0.134 \\
\hline 11 & Copper & Air & PDF'm2yr & 0.1288 \\
\hline 12 & Chromium, ion & Water & PDF'm2yr & 0.05413 \\
\hline 13 & Nickel, ion & Water & PDF'm2yr & 0.04436 \\
\hline 14 & Copper, ion & Water & PDF'm2yr & 0.03762 \\
\hline 15 & Cadmium, ion & Water & PDF'm2yr & 0.03163 \\
\hline 16 & Zinc, ion & Water & PDF'm2yr & 0.02708 \\
\hline 17 & Land use IV-IV & Raw & PDF'm2yr & 0.02189 \\
\hline 18 & Chromium & Soil & PDF'm2yr & 0.01688 \\
\hline 19 & Arsenic & Air & PDF'm2yr & 0.01486 \\
\hline 20 & Cadmium & Soil & PDF'm2yr & 0.01056 \\
\hline 21 & Mercury & Air & PDF'm2yr & 0.005566 \\
\hline 22 & Ammonia & Air & PDF'm2yr & 0.003769 \\
\hline 23 & Lead & Water & PDF'm2yr & 0.002451 \\
\hline 24 & Zinc & Soil & PDF'm2yr & 0.002314 \\
\hline 25 & Arsenic, ion & Water & PDF'm2yr & 0.001239 \\
\hline 26 & Toluene & Water & PDF'm2yr & 0.001005 \\
\hline 27 & Benzene & Water & PDF'm2yr & 0.0003357 \\
\hline
\end{tabular}

Table 3: Damage assessment of 1 ton bitumen production and substances which effect on ecosystem quality.

expressed in DALY/kg emission, resulting from radioactive radiation Ozone layer Damage, expressed in DALY $/ \mathrm{kg}$ emission, due to increased $\mathrm{UV}$ radiation as a result of emission of ozone depleting substances to air. These effects expressed in DALY/kg emission.

Table 2 shows materials which have negative effects on human health during the 1 ton bitumen production, all included processes were described in introduction section. Compartment column shows where the substances release.

Ecosystem quality: Under this category two subcategories, Ecotoxicity and Acidification/ Eutrophication are considered. Ecotoxicity Damage to ecosystem quality, as a result of emission of ecotoxic substances to air, water and soil. Damage is expressed in Potentially Affected Fraction $(\mathrm{PAF})^{*} \mathrm{~m}^{2}{ }^{*}$ year $/ \mathrm{kg}$ emission and Acidification/ Eutrophication Damage to ecosystem quality, as a result of emission of acidifying substances to air, Damage is expressed in Potentially Disappeared Fraction $(\mathrm{PDF})^{\star} \mathrm{m}^{2 *}$ year $/ \mathrm{kg}$ emission.

Table 3 shows all substances that have negative effects on ecosystem quality, these materials are producing from 1 ton bitumen production in different stages, the used unit also described earlier in this paper.

\section{Conclusion}

According to this paper in typical oil refineries the most damage occurs in resources category, in case of Pt unit resources category has 156.9 Pt units per 1 ton bitumen production, it means for obtaining $1 \mathrm{~kg}$ crude oil it will take $42.6 \mathrm{MJ}$ energy. From extraction step to distribution bitumen in markets the most released emissions to the air are; nitrogen oxides, sulfur oxides, carbon dioxide, nickel and methane which all have negative effects on human health category, in this category respiratory inorganics subcategory has the highest effect. In respiratory inorganic subcategory using of diesel in diesel generators has the most negative impact on environment which produces nitrogen oxides to the air.

\section{References}

1. ICCT (2011) An introduction to petroleum refining and the production of ultra-low sulfur gasoline and diesel fuel. International Council of Clean Transportation, Bethesda, Maryland.

2. The Bitumen Industry a global perspective (2011) Asphalt institute Inc and European bitumen association-eurobitume, second edition, USA.

3. Eco Indicator 99 Manual for Designers (2000) Ministry of housing spatia planning and the environment, The Netherlands.

4. PRé (2016) Putting the metrics behind the sustainability: SimaPro Database Manual Methods Library. Netherlands.

5. Kennepohl G (2008) Ashalt pavements and the environment. ISAP Internationa Symposium, Zürich.

6. Lattanzio RK (2014) Canadian Oil Sands: Life-cycle assessments of greenhouse gas emissions. Congressional Research Service, R42537.

7. Azhar Butt A (2014) Life cycle assessment of asphalt roads. Doctoral Thesis, KTH Royal Institute of Technology, Stockholm, Sweden.

8. Galatioto F, Huang Y, Parry T, Bird R, Bell M (2015) Traffic modelling in system boundary expansion of road pavement life cycle assessment. Transportation Research Part D: Transport and Environment 36: 65-75.

9. Han J, Forman GS, Elgowainy A, Cai H, Wang M, et al. (2015) A comparative assessment of resource efficiency in petroleum refining. Fuel Journal 157: 292-298.

10. Smith S, Durham SA (2016) A cradle to gate LCA framework for emissions and energy reduction in concrete pavement mixture design. International Journal of Sustainable Built Environment 5: 23-33.

11. Thomson H, Corbett J, Winebrake J (2015) Natural gas as a marine fuel Journal of Energy Policy 87: 153-167.

12. Banar M, Özdemir A (2015) An evaluation of railway passenger transport in Turkey using life cycle assessment and life cycle cost methods. Transportation Research Part D: Transport and Environment 41: 88-105.

13. Environmental Impact of the Petroleum Industry (2003) Published by the Hazardous Substance Research Centers/South \& Southwest Outreach Program.

14. Normalization (2015) New developments in normalization sets 